\title{
Patterns of Behavioural and Emotional Difficulties through Adolescence: The Influence of Prosocial Skills
}

\author{
Javier Ortuño-Sierra ${ }^{1, *}$, Eduardo Fonseca-Pedrero ${ }^{1,3}$, Sylvia Sastre i Riba ${ }^{1}$, and José Muñiz ${ }^{2,3}$ \\ 1 Department of Educational Sciences University of La Rioja (Spain). \\ 2 Department of Psychology, University of Oviedo (Spain). \\ 3 Center for Biomedical Research in the Mental Health Network (CIBERSAM) (Spain).
}

\begin{abstract}
Título: Patrones de dificultades emocionales y comportamentales durante la adolescencia: la influencia de las habilidades prosociales.

Resumen: El objetivo principal del estudio fue examinar la distribución por clusters del Cuestionario de Capacidades y Dificultades (Strengths and Difficulties Questionnaire; SDQ) y analizar el efecto del sexo y la edad, en una muestra de estudiantes pertenecientes a institutos, con edades entre 14 y 18 años $(N=1474)$. Para el análisis de los datos se realizó un análisis iterativo basado en el procedimiento de K-medias. Una solución de cinco clusters destacó como la más parsimoniosa para diferenciar patrones de síntomas emocionales y comportamentales. El modelo de cinco clusters reveló las siguientes agrupaciones: "ausencia de dificultades y altas puntuaciones prosociales" ( $n=418 ; 28,36 \%)$, "altas puntuaciones en dificultades y bajas en comportamiento prosocial” ( $n=239 ; 16,21 \%)$, "altas puntuaciones en hiperactividad, bajo en el resto de las subescalas de dificultades y alto en capacidades prosociales" ( $n=302 ; 20.49 \%)$, "alto en dificultades emocionales y de relación, bajo en dificultades conductuales y de hiperactividad y alto en capacidades prosociales" $(n=275 ; 18,66 \%)$, y finalmente "dificultades de hiperactividad y niveles medios en el resto de subescalas de dificultades y en las capacidades prosociales" ( $n=239 ; 16,21 \%)$. Este modelo de cinco clusters fue replicado atendiendo al género y la edad. Sin embargo, las diferencias encontradas en la distribución de cada cluster sugieren que las dificultades difieren en función del género y de la edad. Los resultados permiten concluir la mayor presencia de dificultades de tipo externalizante en el caso de los hombres y mayores niveles de dificultades emocionales y capacidades prosociales en el caso de las mujeres.
\end{abstract}

Palabras clave: adolescencia; análisis de clúster; SDQ; problemas emocionales y conductuales; prosocial.

\section{Introduction}

The investigation of children's and adolescent's behavioural patterns in order to improve their well-being and adaptability is becoming increasingly important in the literature (Poulou, 2014). Adolescence is a key stage of development for processes such as gain and acquisition of a new autonomy and the development of an identity in relationship with peers (Piehler, 2011). Different and important progresses take place regarding socio-emotional skills allowing capabilities like empathy, altruistic tendencies, and prosocial behavior (Caprara, Luengo Kanacri, Zuffiano, Gerbino, \& Pastorelli, 2015; Eisenberg, Spinrad, \& Morris, 2013). These abilities enable a more complex social maturity that will introduce adolescents in the adult world.

Processes of synaptic pruning, decrease in gray matter, and myelination, with the increase in white matter, are related to the consolidation of the network of information processing and with improvements in executive control and self-

* Correspondence address [Dirección para correspondencia]:

Javier Ortuño Sierra. Department of Educational Sciences. University of La Rioja. C/ Luis Ulloa S/n. 26002 Logroño (La Rioja, Spain). E-mail: javier.ortuno@unirioja.es
Abstract: The main purpose of the study was to examine the cluster composition of the analysis on the effect of gender and age of the Strengths and Difficulties Questionnaire (SDQ) in a large school-based sample of high school adolescents ranging from 14 to 18 years old $(N=1474)$. In order to do this, a $\mathrm{K}$-means iterative cluster analysis was performed. A five-cluster solution turned out to be the most parsimonious in the differentiation of emotional and behavioural patterns. A five-cluster solution yielded the following patterns: "No difficulties and high prosocial scores" $(n=418 ; 28.36 \%)$, "high difficulties and low prosocial scores" $(n=239$; $16.21 \%$ ), "high on hyperactivity, low on the rest of the difficulties subscales, and high in prosocial capabilities" $(n=302 ; 20.49 \%)$, "high on emotional and peer problems, relatively low on conduct and hyperactivity, and high in prosocial capabilities" ( $n=275 ; 18.66 \%)$, and finally "hyperactivity problems and average in the others difficulties subscales, and in prosocial capabilities" ( $n=239 ; 16.21 \%)$. This cluster solution was replicated attending to the same gender and age groups. Nevertheless, differences in the distribution of the cluster composition suggest that difficulties differ by gender and age. The results allow for the conclusion that men reveal a greater number of problems of an externalizing nature whereas women indicate a greater degree of internalizing difficulties and prosocial skills. Key words: adolescence; cluster analysis; SDQ; emotional and behavioural problems; prosocial.

regulation (Blakemore \& Frith, 2007; Kays, Hurley, \& Taber, 2012). In addition, a stronger connection between orbitofrontal cortex and different structures of the limbic system such as hippocampus, caudate nucleus, and the amygdala is established (Eshel, Nelson, Blair, Pine, \& Ernst, 2007). Such structural and functional changes have an impact on the improvement of cognitive control, inhibition of negative emotions, and in the management of social information relevant to behaviour (Gogtay et al., 2004; Steinberg, 2013). These transformations supported cognitive changes that will manifest throughout adolescence, extending into adulthood. Hormonal changes appear suddenly, however, from early adolescence to middle adolescence. This lack of synchrony between brain and hormonal changes generates a gap or mismatch between cognitive, emotional changes, and selfregulation capabilities, that is especially relevant during early and middle-adolescence, being compensated during late adolescence (Worthman, 2011).

Moreover, there are different stressful situations that adolescents have to deal with from a development point of view. For instance, the acquisition of functional autonomy, academic challenges, new social situations, and decisions related to the academic or professional future. These aspects, and others related to interpersonal and emotional conflicts 
may increase the vulnerability to internalizing (e.g., emotional problems) and externalizing difficulties (e.g., peer problems) (Aebi, Giger, Plattner, Winkler Metzke, \& Steinhausen, 2014; Estévez Gutiérrez, Herrero Fernández, Sarabia Gonzalvo, \& Jáuregui Bilbao, 2014; Forns, Abad, \& Kirchner, 2011; Worthman, 2011) that can persist until adulthood (Brimblecombe et al., 2015; Moscoso, Jovanovic, \& Rojnic, 2015). Internalizing problems are those related to anxiety, social isolation, or difficulties in the relationship with peers. Externalizing problems are related to impulsivity and disruptive behaviours (Achenbach, 1966, 2009). In this regard, early adolescence is a sensitive period for these kind of difficulties, in which adolescents are more vulnerable to the presentation of difficulties and mental problems from midadolescence (Costello, Copeland, \& Angold, 2011; Polanczyk, Salum, Sugaya, Caye, \& Rohde, 2015). It is also worth noting that the different psychological difficulties during adolescence have been found to differ by gender. Females tend to show more Internalizing problems, whereas males are more likely to show Externalizing problems (Achenbach, 2009; Di Riso et al., 2010; Giannakopoulos et al., 2009; Van Roy, Grøholt, Heyerdahl, \& Clench-Aas, 2010; Yao et al., 2009). For instance, different studies concluded that females show higher scores in aspects like empathy, sympathy, and prosocial behaviour than males (Caprara et al., 2015; Di Riso et al., 2010; Luengo Kanacri et al., 2014; Mestre, Carlo, Samper, Tur-Porcar, \& Mestre, 2015; OrtuñoSierra, Fonseca-Pedrero, Paino, \& Aritio-Solana, 2014; van Widenfelt, Goedhart, Treffers, \& Goodman, 2003; Yao et al., 2009). In the study of Yao et al. (2009) females showed more emotional problems, whereas males reported higher scores in conduct problems and hyperactivity.

In this process there are a number of factors that act as mediators or moderators, and that have a deep impact on the vulnerabilities mentioned (Roisman, Masten, Coatsworth, \& Tellegen, 2004; Uggen \& Massoglia, 2003). Adolescents who are able to establish close and intimate social relationships with peers have better chances of reaching a good adjustment and satisfaction with life, while those showing greater difficulties in social relationships have a greater likelihood of developing an increased number of internalizing and externalizing difficulties (Allen et al., 2002; Giannotta, Ortega, \& Stattin, 2012; McElhaney, Immele, Smith, \& Allen, 2006; Goñi, Esnaola, Rodríguez, \& Camino, 2015; Scott, Briskman, Woolgar, Humayun, \& O’Connor, 2011).

Thus, the establishment of close relations with peers and the development of prosocial behaviours are important markers that predict future adjustment, including manifestations like antisocial behavior or aggression (Carlo et al., 2014). In this regard, personal variables such as empathy, sympathy or perspective taking have been found to play a key role in the acquisition and development of prosocial behaviours (Mestre et al., 2015). In addition, some variables such as self-efficacy have more recently shown a big impact in the regulation and manifestation of different difficulties in this stage (Areces, Rodríguez Muñiz, Suárez Álvarez, de la
Roca, \& Cueli, 2016; Junttila \& Vauras, 2014; Leff et al., 2014). The failure in achieving these tasks is related to patterns of aggression in relationships of friendship, getting along with the presentation of symptoms internalizing and externalizing in adolescence and adulthood (Chango, McElhaney, \& Allen, 2009). Similarly, patterns of withdrawal, social isolation, and rejection of companions predict an increase in depressive symptoms (Galambos \& Krahn, 2008). Different researches have explored the links between isolated social skills and children's psychological adjustment (Pakaslahti, Karjalainen, \& Keltikangas-Jarvinen, 2002; Petrides, Frederickson, \& Furnham, 2004). Furthermore, the establishment of appropriate social relations would appear to play an important role in the reduction and cessation of externalizing behavior (Barker \& Galambos, 2007; Giordano, Manning, \& Longmore, 2005; Halpern-Meekin, Manning, Giordano, \& Longmore, 2013). For instance, Ogden (2001) showed that socially competent students were less likely to engage in behavioural problems, had more abilities in conflict resolution and problem solving, and were at the same time, better at making friends than their more disruptive peers.

Within this framework, the Strengths and Difficulties Questionnaire (SDQ) (Goodman, 1997), self-report form, is a screening instrument for behavioural and emotional problems that similarly allows the assessment of capacities in the social sphere. The SDQ is composed of 25 items, which are grouped into five subscales: Emotional symptoms (e.g. I woryy a lot), Conduct problems (e.g. I am often accused of lying or cheating), Hyperactivity (e.g. I am restless, I cannot stay still for long), Peer problems (e.g. Other children or young people pick on me or bully me), and Prosocial behaviour (e.g. I try to be nice to other people. I care about their feelings). The first four subscales form a Total difficulties score. In total, 15 items reflect problems and 10 strengths, of which five belong to the Prosocial subscale and five should be recoded, given that they belong to the Total difficulties score. The inclusion of these positive items increased the acceptability of the measuring instrument between parents and teacher. In addition, it addresses contemporary issues like impulsiveness or bulling so it is widely accepted by clinicians. Previous studies have indicated an adequate reliability of the scores in the self-report version of the SDQ (Gómez, 2012; Ortuño-Sierra, Fonseca-Pedrero, Paino, Sastre i Riba, \& Muñiz, 2015a). In addition, evidences of the internal structure of the document have been gathered, revealing both a three and five factor-model as the most appropriate (Essau et al., 2012; He, Burstein, Schmitz, \& Merikangas, 2013; Ortuño-Sierra et al., 2015b; Ruchkin, Jones, Vermeiren, \& Schwab-Stone, 2008).

Several previous studies have shown the co-occurrence of psychological difficulties related to emotional and relationship problems as well as problems associated with attention-deficit hyperactivity disorder (ADHD), conduct disorder (CD) or oppositional defiant disorder (ODD). For instance, in the study of Sonunga-Barke, Thompson, Stevenson, \& Viney (1997), pre-school children could be catego- 
rized into six groups based on their scores on the Behavioural Checklist (Achenbach \& Rescorla, 2001). The first and largest group contained children with no problems, and three other groups had children with specific but low-level issues. The remaining two groups of children displayed greater conduct problems; for one group this was combined with significant emotional difficulties and for the other with extreme hyperactivity. A more recent study (Bradshaw \& Tipping, 2010), conducted in Scotland using cluster analysis with the SDQ, revealed that it was possible to divide children into five groups based on their characteristics across the five SDQ subscales. Some of the clusters included students with Internalizing problems, Externalizing problems, students with no difficulties and good prosocial capabilities, students with difficulties in the hyperactive subscale, and students with difficulties in all the subscales, including the prosocial subscale.

Taking into account the relation between the prosocial capabilities and the manifestation of different behavioural and emotional difficulties during adolescence, it seems crucial detecting prosocial abilities in early stages of development as well as to study the relationship between prosocial skills and behavioural and emotional difficulties. In this regard, the inclusion of the SDQ as a screening tool in school context is beneficial as it allows screening for internalizing, externalizing difficulties along with prosocial skills. Nevertheless, there has been no in-depth examination addressing the role that prosocial skills play in adolescent adjustment and well-being using the SDQ. Also, and to the best of our knowledge, although the SDQ is widely used as a screening tool in different settings, only one study has analyzed the distribution of psychological difficulties in adolescents with the SDQ through cluster analysis (Bradshaw \& Tipping, 2010). Previous studies have focused on the items aggrupation rather than participant's aggrupation. The study of participant's aggrupation allows for a better knowledge of behavioural patterns and may allow for the detection of those adolescents at high risk for mental problems and thus facilitate for the implementation of early prevention and intervention programs.

Therefore, the main goal of the present study is to study the cluster composition of the SDQ in a large school-based sample of high-school students. In addition, the cluster distribution regarding gender and age will be examined. Extrapolating from the existing previous study, a five cluster composition is expected. The same cluster composition is expected with regards to gender and the age. In addition, those adolescents with more prosocial capabilities are expected to have fewer incidences of psychological difficulties.

\section{Method}

\section{Participants}

Part of the data used in the present study has been published elsewhere (Fonseca-Pedrero, Paino, Lemos Giraldez, \& Muñiiz, 2010; Ortuño-Sierra et al., 2015a). Selection of participants was made by means of stratified random sampling, by clusters, at the classroom level, in a population of approximately 36,000 students from the Principality of Asturias (a region situated in the north of Spain). Strata were created according to geographical area -East, West, Central, and South- and educational stage -compulsory and postcompulsory-, and the probability of a school being selected depended on the number of students. Schools were contacted via telephone and letter. All the schools approved to take part in the study. Students were from different types of secondary schools - public, grant-assisted private and private and from vocational/technical schools. The initial sampling was formed by 1628 students, eliminating participants who presented: a) a high score in The Oviedo Infrequency Scale (more than two points) $(n=64)$; b) learning difficulties $(n=$ $6)$; c) omission of demographics or a high percentage of items without responding $(n=48)$; and d) outliers scores $(n$ =36). Thus, the final sample comprised a total of 1474,756 male students (48.6\%), belonging to 28 schools and 90 classrooms. The age of the participants ranged from 14 to18 years $(M=15.92$ years; $S D=1.18)$. The age distribution of the sample was the following: 14 years $(n=194 ; 14.7 \%), 15$ years $(n=357 ; 27.1 \%), 16$ years $(n=411 ; 31.2 \%), 17$ years $(n$ $=357 ; 27.1 \%)$, and 18 years $(n=137 ; 9.3 \%)$.

\section{Instruments}

The Strengths and Difficulties Questionnaire (SDQ) (Goodman, 1997), self-reported form. The SDQ is made up of a total of 25 statements distributed across five subscales (each with five items): Emotional Symptoms, Conduct Problems, Hyperactivity, Peer Problems, and Prosocial Behaviour. The first four subscales yield a Total Difficulties score. In this study we used a Likert-type response format with five options $(1=$ "totally disagree" to $5=$ "totally agree"), so that the score on each subscale ranged from 5 to 25 points. In the present study we used the version adapted and translated into Spanish in a non-clinical adolescent population. Spanish version of the SDQ have shown adequate psychometric properties (Ortuño-Sierra et al., 2015a; Ortuño-Sierra et al., 2015b).

The Oviedo Infrequency Scale (INF-OV) (FonsecaPedrero, Lemos-Giráldez, Paino-Pineiro, Villazón-García, \& Muñiz, 2009). INF-OV is a 12 -item self-report instrument with a Likert-type response format using five categories $(1=$ "totally disagree" to $5=$ "totally agree"). Its objective is to detect those participants who respond to self-reports in a random, pseudo-random or dishonest fashion. Once the items were 
dichotomized, participants who scored more than two items incorrectly were eliminated from the study.

\section{Procedure}

The questionnaires were administered collectively, in groups of 10 to 35 students, during normal school time and in a classroom specially prepared for this purpose. For participants under 18, parents were asked to provide written informed consent in order for their child to participate in the study. Participants were informed of the confidentiality of their responses and the voluntary nature of the study, and no incentive was provided for their collaboration.The administration took place under the supervision of the researchers. The study was approved by the research and ethics committees at the University of Oviedo and by the Department of Education of the Principality of Asturias.

\section{Data analyses}

We performed data clustering techniques to identify subgroups of adolescents with emotional and behavioural problems and prosocial capabilities. We performed a K-means iterative cluster analysis with the SDQ subscales. As only one previous study has been conducted, we decided to study a different cluster solution in an exploratory attempt.

We then carried out a multivariate analysis of variance (MANOVA) using the cluster assignment as the independent variable and the SDQ scores as the dependent variables, in order to obtain a discriminative index for the clusters created. With the aim of analysing the distribution of the clusters regarding age, we divided the total sample into two subgroups (14-15 year-olds and 16-18 year-olds), according to the different stages of adolescence: initial adolescence and middle-late adolescence (Salmera-Aro, 2011). It is worth noting that these ages also relate to the different stages of the Spanish educational system (compulsory/post-compulsory), although the final inclusion criteria was that of age. In order to study the cluster distribution by gender and age we performed a K-means iterative cluster analysis with the two gender's groups (males and females) and the two ages' groups (14-15 and 16-18). In addition, we studied the descriptive composition of the clusters in the general group attending to gender and age. SPSS 22.0 (IBM Corp. Released, 2013) was used for data analyses.

\section{Results}

\section{Cluster analysis}

The agglomeration schedule supported that the passage from five to four clusters would have more impact on the heterogeneity of the clusters than previous stages of the analysis, as continuing to regroup the clusters would result in joining together quite different clusters at this stage. Cluster memberships were then determined through consecutive non-hierarchical K-means cluster analysis computed to identify an optimal five-cluster solution.

A k-means cluster analysis on all 1474 students, forcing five cluster, yielded the following results (see Table 1). Cluster 1 consisted of $240(16.28 \%)$ participants and reflected high scores on conduct and hyperactivity problems, low scores on measures of emotional and peer problems, and low prosocial capabilities. Cluster 2 was the largest cluster, consisting of $418(28.36 \%)$ participants who scored low on all the difficulties subscales and that reported the higher scores on prosocial capabilities. Cluster 3 was composed of 302 $(20.49 \%)$ participants that scored high on hyperactivity, low on the rest of the difficulties subscales, and high in prosocial capabilities. Cluster 4 was composed of 275 (18.66\%) participants that scored high on emotional and peer problems, relatively low on conduct and hyperactivity, and high in prosocial capabilities. Finally, cluster 5 was composed of 239 $(16.21 \%)$ who scored high on all the difficulties subscales and low on the prosocial capabilities (see Table 1). The profiles of the five clusters are depicted in Figure 1.

The MANOVA conducted revealed a main significant effect of cluster membership. The Wilks' $\lambda$ multivariate results revealed statistically significant differences $(\lambda=0.108, F$ $(20,4859)=232,716, p<0.001$, partial $\left.\eta^{2}=0.427\right)$. Descriptive statistics for each cluster and MANOVA are reported in Table 1 . As it can be seen, those adolescents reporting lower levels of prosocial skills (Cluster 1) were, at the same time, those who showed more conduct $(M=12.64)$ and hyperactive $(M=14.28)$ difficulties, as well as those adolescents of Cluster number 5 who revealed even higher conduct $(M=$ 13.47) and hyperactive $(M=18.82)$ difficulties. Also, it is worth noting that adolescents who scored high in prosocial abilities $(M=20.70)$, reported the highest levels of emotional $(M=16.86)$ and peers difficulties $(M=12.15)$.

The scheffé post hoc analyses, attending the different subscales, revealed that in the Emotional Problems subscale, there were statistically significant differences between the Clusters $(1>3 ; 4>1,2,3,5 ; 5>1,3)$ bigger than with the exception of the relation between Clusters 1 and 2, and Clusters 2 and 3. With regards to the Behavioural Problems subscale, all the Cluster showed statistically significant differences $(1>2,3 ; 3>2 ; 4>2,3 ; 5>1,2,3,4)$ with the exception of Cluster 1 and 4 . No differences were found between Cluster 1 and 5 and Cluster 2 and 3 in Peer Problems subscale, with the rest being statistically significant different $(1>$ $3 ; 4>1,2,3,5 ; 5>2,3)$. Also in Hyperactivity subscale, all the Clusters comparison were statistically significant $(1>2$; $3>1,2,4 ; 4>2 ; 5>1,2,3,4)$ with the exception of Cluster 1 and 4 . In the Prosocial subscale statistically significant differences were found between the Clusters $(2>1,5 ; 3>1,5$; $4>1,5 ; 5>1$ ) with the exception of Cluster 2 and 3 , Cluster 2 and 4, and Cluster 3 and 4). Finally, and in relation to the Total Difficulties score, all the Cluster showed statistically significant differences $(1>2,3 ; 3>2 ; 4>1,2,3 ; 5>1,2$, 3 ) with the exception of the relation between Cluster 1 and 3 and Cluster 4 and 5. 
Table 1. MANOVAs' results and descriptive statistics of the five-cluster solution.

\begin{tabular}{|c|c|c|c|c|c|c|c|c|}
\hline & $\begin{array}{c}\text { Cluster } 1 \\
(N=240, \\
16.28 \%)\end{array}$ & $\begin{array}{c}\text { Cluster } 2 \\
(N=418, \\
28.36 \%)\end{array}$ & $\begin{array}{c}\text { Cluster } 3 \\
(N=302, \\
20.49 \%)\end{array}$ & $\begin{array}{c}\text { Cluster } 4 \\
(N=275 \text {, } \\
18.66 \%)\end{array}$ & $\begin{array}{c}\text { Cluster } 5 \\
(N=239, \\
16.21 \%)\end{array}$ & $\begin{array}{c}\text { Total } \\
(N=1474)\end{array}$ & & \\
\hline SDQ & $M(S D)$ & $M(S D)$ & $M(S D)$ & $M(S D)$ & $M(S D)$ & $M(S D)$ & $F$ & $p$ \\
\hline Emotional & $9.98(2.25)$ & $10.12(2.76)$ & $10.15(2.63)$ & $16.86(2.83)$ & $15.06(3.10)$ & $12.16(3.96)$ & 409.45 & $<.01$ \\
\hline Conduct & $12.64(2.67)$ & $7.89(1.79)$ & $9.48(1.95)$ & $10.41(2.65)$ & $13.47(3.04)$ & $10.36(3.15)$ & 280.01 & $<.01$ \\
\hline Peer Problems & $9.30(2.32)$ & $8.44(2.14)$ & $7.61(1.66)$ & $12.15(3.51)$ & 9.45 (2.57) & $9.26(2.90)$ & 139.21 & $<.01$ \\
\hline Hyperactivity & $14.28(2.79)$ & $10.55(2.16)$ & $16.66(2.27)$ & $13.83(2.71)$ & $18.82(2.73)$ & $14.36(3.83)$ & 502.80 & $<.01$ \\
\hline Prosocial & $17.68(2.40)$ & $21.37(2.24)$ & $21.06(2.12)$ & $20.70(2.53)$ & $19.90(2.86)$ & $20.34(2.72)$ & 102.15 & $<.01$ \\
\hline Total Difficulties & $46.19(5.20)$ & $39.99(4.99)$ & $43.89(4.36)$ & $53.24(6.58)$ & $56.80(6.56)$ & $46.15(9.11)$ & 636.85 & $<.01$ \\
\hline
\end{tabular}

Note. SDQ= Strengths and Difficulties Questionnaire; $M=$ Mean; $S D=$ Standard Deviation.

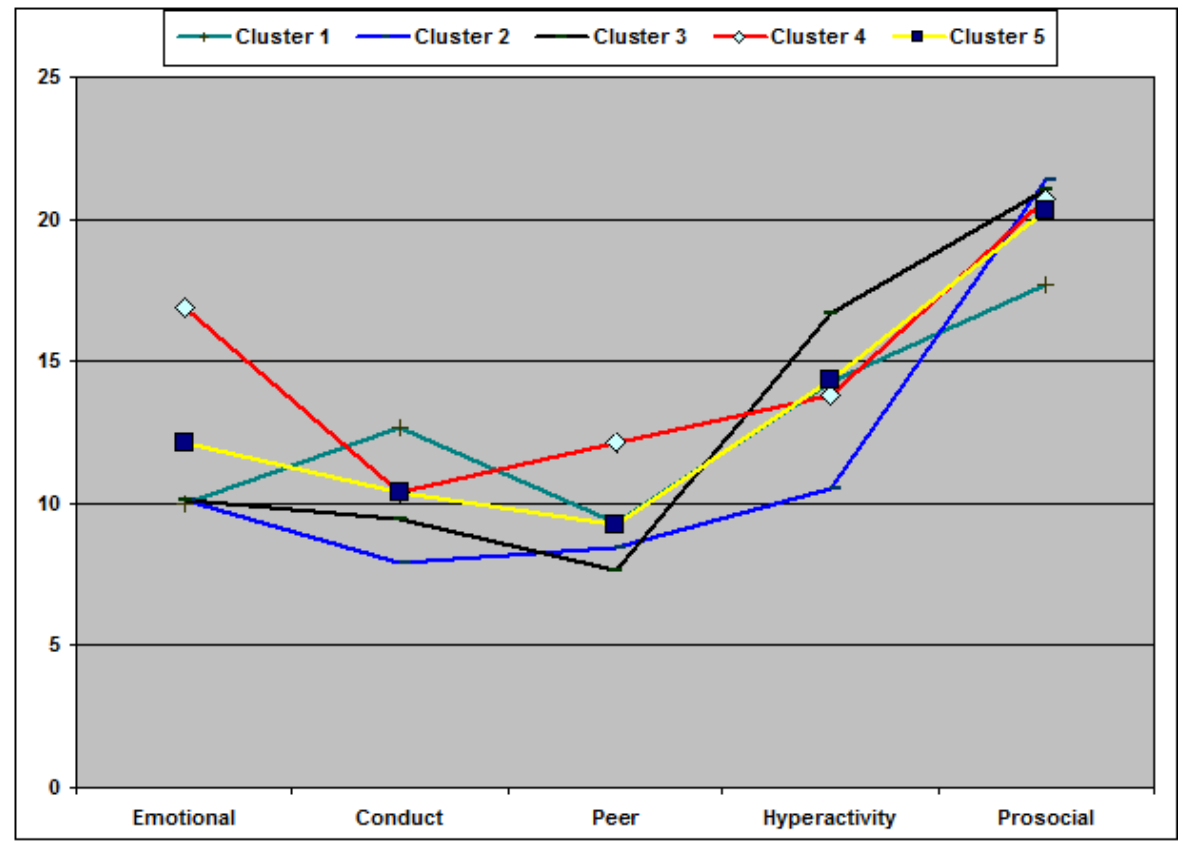

Figure 1. Five-cluster solution for the Strengths and Difficulties Questionnaire subscales.

\section{Cluster analysis and distribution by gender and age}

Once the cluster composition was studied in the total sample, we then decided to undertake a k-means cluster analysis attending to gender and age. Similarly to the total sample, the analysis revealed that a five-cluster solution was the most feasible in males and females and in the younger (14-15 years old) and the older groups (16-18 years old).

We also studied the total amount of students belonging to each cluster of the final sample, attending to gender and age. As can be seen in Table 2, the largest amount was found in Cluster 1 (high scores on conduct and hyperactivity problems, low emotional and peer problems, and low prosocial capabilities), with $25.28 \%$ of males and $7.79 \%$ of females, and Cluster 4 (high on emotional and peer problems and high in prosocial capabilities) with $12.71 \%$ of males and $30.74 \%$ of females.

With regards to age, the bigger differences were found in Cluster 1 with $18.56 \%$ of younger students and $14.91 \%$ of the older group, and Cluster 3 where the older group was overrepresented $(20.78 \%)$ compared to the younger group (14.62\%).

Table 2. Cluster distribution by gender and age.

\begin{tabular}{lcccc}
\hline & \multicolumn{2}{c}{ Gender } & \multicolumn{2}{c}{ Age } \\
\cline { 2 - 5 } Cluster & Males & Females & $14-15$ years & $16-18$ years \\
1 & $N(\%)$ & $N(\%)$ & $N(\%)$ & $N(\%)$ \\
\cline { 2 - 5 } 2 & $181(25.28)$ & $59(7.79)$ & $103(18.56)$ & $137(14.91)$ \\
3 & $185(25.84)$ & $233(24.27)$ & $160(28.83)$ & $258(28.07)$ \\
4 & $149(20.81)$ & $153(20.18)$ & $111(14.62)$ & $191(20.78)$ \\
5 & $91(12.71)$ & $184(30.74)$ & $102(18.38)$ & $173(18.82)$ \\
\hline
\end{tabular}

\section{Discussions and Conclusions}

The main purpose of the present work was to study the cluster composition of the Strengths and Difficulties Questionnaire (SDQ) in a large school based sample of high school adolescents and analyze the effect of gender and age. Different studies have indicated the key role that prosocial skills 
play in the adjustment and well-being in children and specifically adolescents (Caprara et al., 2015; Carlo et al., 2014; Luengo Kanacri et al., 2014). The study of participant association allows for a better knowledge of behavioural and emotional patterns in adolescents as well as the detection of adolescents at risk. The understanding of the associations between psychological difficulties and prosocial skills in males and females during adolescence could allow establishing different profiles of adolescents that are more likely to develop more severe mental problems (Berger, Batanova, \& Duncan Cance, 2015; Junttila \& Vauras, 2014; Riglin et al., 2015).

The cluster analysis produced five groups of children based on their scores on the five SDQ subscales. The largest group was the group in which adolescents had the lowest levels of difficulties. Adolescents in this group showed the highest scores in prosocial capabilities. The second largest group was cluster 3 . In this case, adolescents showed high scores for prosocial behaviour and generally low scores for emotional symptoms, conduct problems, and peer relationship problems. However, adolescents in this cluster have higher than average scores for hyperactivity/inattention. This pattern could suggest that some teenagers considered as boisterous or with certain attentional problems, do not necessarily exhibit particularly challenging behavior. Another cluster also revealed high levels of Internalizing problems and high scores in emotional and peer problems. The cluster solution found in the present work is similar to the one found by Bradshaw and Tipping (2010) in their study with Scottish children. They revealed a five-cluster solution including students with Internalizing problems, Externalizing problems, students with no difficulties and good prosocial capabilities, students with difficulties in the hyperactive subscale, and students with difficulties in all the subscales, including the prosocial subscale.

It is worth noting that adolescents in this group showed appropriate scores in prosocial capabilities. The clusters with a lower amount of students were cluster 1 and 5. This suggests that students showing Externalizing problems (Cluster 1) or students showing problems in all the areas are less common. Also, it is remarkable that adolescents in these two clusters showed the lower scores in prosocial capabilities. Thus, adolescents with prosocial capabilities are less likely to have externalizing problems in particular and psychological problems in general. These results support the idea that adolescent with prosocial capabilities are less likely to have different difficulties, including Externalizing problems such as conduct difficulties or hyperactive (Caprara et al., 2015; Carlo et al., 2014). The relation between prosocial abilities and Internalizing problems has also been shown in a recent study with 937 adolescents in Spain by means of structural equation modeling (Llorca Mestre, Mesurado, \& Samper García, 2014), and also in the international context (Batanova \& Loukas, 2014)

Prosocial abilities are considered a protective factor in the onset and maintenance of psychological problems during childhood and adolescence (Allen et al., 2002; Giannotta et al., 2012; McElhaney et al., 2006; Scott et al., 2011). The results found confirm the idea that adolescents with less psychological difficulties are those that have more prosocial abilities. By this token, those adolescents with more psychological problems have less prosocial abilities. Therefore, intervention in the school context should focus not only in the detection of psychological problems, but also in the intervention and development of social abilities and skills in children and teenagers.

The results also indicated that the five clusters found are consistent both in gender and age. In the case of the gender, the study of the cluster revealed that there were more females included in the Cluster related to Internalizing problems. In this case, prosocial abilities were also high. This is consistent with previous studies indicating that females have more Internalizing problems (Di Riso et al., 2010; OrtuñoSierra et al., 2014; Yao et al., 2009). Also, males are overrepresented in the Cluster that reflect conduct problems and hyperactivity which are considered Externalizing problems. This is also consistent with previous studies indicating that males tend to show more externalizing problems than females (Di Riso et al., 2010; Ortuño-Sierra et al., 2014). For instance, Yao et al (2009), indicated that females showed more emotional problems, whereas males reported higher scores in conduct problems and hyperactivity.

The Clusters study also allows capturing the different groups of teenagers and the proportion of members in each group through. The same five cluster solution was found when the two ages' groups (14-15 and 16-18) were considered. Nevertheless, the proportion of younger adolescents was higher in the Cluster related to Externalizing problems and lower prosocial capabilities, when compared with the older group. Previous studies have found contradictory results with regards to the age and the presentation of difficulties with the SDQ (Giannakopoulos et al., 2009; Koskelainen, Sourander, \& Vauras, 2001; Rønning, Helge Handegaard, Sourander, \& Mørch, 2004; Yao et al., 2009). However, other studies indicated similar results, with younger adolescents showing more Externalizing problems (Armand, Keypour, Maracy, \& Attari, 2012; Lien, Green, Welander-Vatn, \& Bjertness, 2009). For instance, Armand, Keypour, Maracy y Attari (2012), with $n=2000$ children and adolescents from Iran revealed that Externalizing problems and total difficulties were higher in younger teenagers. The results found seem to be consistent with the existence of a lack of synchrony between brain and hormonal changes that generates a gap or mismatch between cognitive, emotional changes, and self-regulation capabilities. This gap is especially relevant during early and middle-adolescence, being compensated during late adolescence (Worthman, 2011). Thus, physical, cognitive, and social changes during adolescence determine the presentation of psychological difficulties. For this reason, intervention in the first stages of adolescence or even earlier during childhood, promoting the acquisition and development of prosocial capabilities is advisable in order to 
prevent future difficulties that might affect in a more severe way (Caprara et al., 2015).

The present study should be interpreted in the light of the following limitations. First of all, a limitation of the study is the sole reliance on self-report measures. Although confidentiality was assured, self-report bias possibly confounds the inferences (Navarro-González, Lorenzo-Seva \& VigilColet, 2016). An additional improvement on the present design would be to include different measures from parents and teachers. Second, although the sample size in the present study was large and likely representative of the student population from which the sample was obtained, there are still limitations to the external validity of the study. For example, high school students were recruited from high schools in a north region of Spain; whether these results hold for samples from other geographic regions in Spain, or even more for other samples of adolescents in Europe, is a question for further research to address. In this sense, due to the lack of research about the cluster distribution of emotional, behavioural, and social difficulties by means of the SDQ, it has only been possible to compare our results with one previous study. Finally, the inclusion of other measurement instruments in the study would have allowed the validation of the

\section{References}

Achenbach, T. M. (1966). The classification of children's psychiatric symptoms: A factor-analytic study. Psychological Monographs, 80, 1-37.

Achenbach, T. M. (2009). The Achenbach System of Empirically Based Assessment (ASEBA): Development, findings, theory, and applications. Burlington, VT: University of Vermont Research Centre for Children, Youth and Families.

Achenbach, T. M., \& Rescorla, L. A. (2001). Manual for the ASEBA SchoolAge Forms \& Profiles. University of Vermont, Research Center for Children, Youth, \& Families: Burlington, VT.

Aebi, M., Giger, J., Plattner, B., Winkler Metzke, C., \& Steinhausen, H.-C. (2014). Problem coping skills, psychosocial adversities and mental health problems in children and adolescents as predictors of criminal outcomes in young adulthood. European Child \& Adolescent Psychiatry, 23(5), 283-293.

Allen, J. P., Marsh, P., Mcfarland, C., Mcelhaney, K. B., Land, D. J., Jodl, K. M., \& Peck, S. (2002). Attachment and autonomy as predictors of the development of social skills and delinquency during midadolescence. Journal of Consulting and Clinical Psychology, 70(1), 55-66.

Areces, D., Rodríguez Muñiz, L.J., Suárez Álvarez, J., de la Roca, Y., \& Cueli M. (2016). Information sources used by high school students in the college degree choice. Psicothema, 28, 253-259.

Armand, S., Keypour, M., Maracy, M. R., \& Attari, A. (2012). Epidemiological study of youth mental health using Strengths and Difficulties Questionnaire (SDQ). Iranian Red Crescent Medical Journal, 14(6), 371-375.

Barker, E. T., \& Galambos, N. L. (2007). Body dissatisfaction, living away from parents, and poor social adjustment predict binge eating symptoms in young women making the transition to university. Journal of Youth and Adolescence, 36, 904-911.

Batanova, M., \& Loukas, A. (2014). Unique and interactive effects of empathy, family, and school factors on early adolescents' aggression. Journal of Youth and Adolescence, 43(11), 1890-1902.

Berger, C., Batanova, M., \& Duncan Cance, J. (2015). Aggressive and prosocial? Examining latent profiles of behavior, social status, machiavellianism, and empathy. Journal of Youth and Adolescence 1-15. DOI 10.1007/s10964-015-0298-9

Blakemore, S., \& Frith, U. (2007). ¿Cómo aprende el cerebro? Barcelona: Ariel. clusters obtained with educational, well-being, or affect variables.

In this regard, the present study contributes new information as there is only one previous study (Bradshaw \& Tipping, 2010), to best of our knowledge, that confirms the existence of groups of adolescents through Cluster analysis that show these characteristics. As the SDQ is a widely used measurement instrument for the assessment of prosocial, emotional, and behavioural difficulties in children and adolescents, future studies may well continue to investigate the presentation of these problems in these populations by means of cluster composition. Also, new studies with this technique will allow comparing the group composition in different regions of the country or in different cultures and/or nations. In addition, the inclusion of different measurement instruments (e.g., trauma experiences, coping strategies, substance use, etc.) could permit the cluster validation with other external sources.

Acknowledgments.- This research was funded Spanish Ministry of Science and Innovation (PSI 2014-56114-P, EDU 2016-78440-P). BBVA Foundation for researchers and creative artists 2015, Grant/Award Number: N[15]_CJS_PSI_0662.

Bradshaw, P., \& Tipping, S. (2010). Growing up in Scotland: Children's social, emotional and behavioural characteristics at entry to primary school. Edinburgh: Scottish Government.

Brimblecombe, N., Knapp, M., Murguia, S., Mbeah-Bankas, H., Crane, S., Harris, A., . . . King, D. (2015). The role of youth mental health services in the treatment of young people with serious mental illness: 2 year outcomes and economic implications. Early intervention psychiatry, 1. doi:10.1111/eip.12261

Caprara, G. V., Luengo Kanacri, B. P., Zuffiano, A., Gerbino, M., \& Pastorelli, C. (2015). Why and How to Promote Adolescents' Prosocial Behaviors: Direct, Mediated and Moderated Effects of the CEPIDEA School-Based Program. Journal of Youth and Adolescence doi:10.1007/s10964-015-0293-1

Carlo, G., Mestre, M. V., McGinley, M. M., Tur-Porcar, A., Samper, P., \& Opal, D. (2014). The protective role of prosocial behaviors on antisocial behaviors: the mediating effects of deviant peer affiliation. Journal of Adolescence, 37, 359-366. doi:10.1016/j.adolescence.2014.02.009

Costello, E. J., Copeland, W., \& Angold, A. (2011). Trends in psychopathology across the adolescent years: What changes when children become adolescents, and when adolescents become adults? Journal Of Child Psychology \& Psychiatry, 52(10), 1015-1025. doi:doi:10.1111/j.1469-7610.2011.02446.x

Chango, J., McElhaney, K., \& Allen, J. P. (2009). Attachment organization and patterns of conflict resolution in friendships predicting adolescents' depressive symptoms over time. Attachment \& Human Development, 11(4), 331-346.

Di Riso, D., Salcuni, S., Chessa, D., Raudino, A., Lis, A., \& Altoè, G. (2010). The Strengths and Difficulties Questionnaire (SDQ). Early evidence of its reliability and validity in a community sample of Italian children. Personality and Individual Differences, 49, 570-575.

Eisenberg, N., Spinrad, T. L., \& Morris, A. S. (2013). Prosocial development. In P. Zelazo (Ed.), Oxford Handbook of Developmental Psychology. New York: Oxford University Press.

Eshel, N., Nelson, E. E., Blair, R. J., Pine, D. S., \& Ernst, M. (2007). Neural substrates of choice selection in adults and adolescents: Development 
of the ventrolateral prefrontal and anterior cingulated cortices. Neuropsychologia, 45, 1270-1279.

Estévez Gutiérrez, A,. Herrero Fernández, D., Sarabia Gonzalvo, I., \& Jáuregui Bilbao, P. (2014). El papel mediador de la regulación emocional entre el juego patológico, uso abusivo de Internet y videojuegos y la sintomatología disfuncional en jóvenes y adolescentes. Adicciones, 26, 282-290.

Essau, C. A., Olaya, B., Anastassiou-Hadjicharalambous, X., Pauli, G., Gilvarry, C., Bray, D., . . . Ollendick, T. H. (2012). Psychometric properties of the Strength and Difficulties Questionnaire from five European countries. International Journal of Methods in Psychiatry Research, 21(3), 232-245. doi:10.1002/mpr.1364

Fonseca-Pedrero, E., Paino, M., Lemos Giraldez, S., \& Muñiz, J. (2011). Prevalencia de la sintomatología emocional y comportamental en adolescentes españooles a través del Strength and Difficulties Questionnaire (SDQ). Revista de Psicopatología y Psicología Clinica, 16, 15 25.

Fonseca-Pedrero, E., Lemos-Giráldez, S., Paino-Pineiro, M., VillazónGarcía, U., \& Muñiz, J. (2009). Validation of the Schizotypal Personality Questionnaire-Brief Form in adolescents. Schizophrenia Research, 111, 53-60. doi:doi:10.1016/j.schres.2009.03.006

Forns, M., Abad, J., \& Kirchner, T. (2011). Internalizing and Externalizing Problems. In R. J. R. Levesque (Ed.), Encyclopedia of Adolescence (pp. 1464-1469). Springer: New York.

Galambos, N. L., \& Krahn, H. J. (2008). Depression and anger trajectories during the transition to adulthood. Journal of Marriage and the Family, 70, $15-27$.

Giannakopoulos, G., Tzavara, C., Dimitrakaki, C., Kolaitis, G., Rotsika, V. \& Tountas, Y. (2009). The factor structure of the Strengths and Difficulties Questionnaire (SDQ) in Greek adolescents. Annals of General Psychiatry, 8, 20.

Giannotta, F., Ortega, E., \& Stattin, H. (2012). An attachment parenting intervention to prevent adolescents' problem behaviors: A pilot study in Italy. Child and Youth Care Forum. doi:10.1007/s10566-012-9189-3

Giordano, P., Manning, W., \& Longmore, M. (2005). The Romantic Relationships of African American and White Adolescents. Sociological Quarterly, 46, 545-568.

Gogtay, N., Giedd, J. N., Lusk, L., Hayashi, K. M., Greenstein, D., Vaituzis, C., . . . Thompson, P. M. (2004). Dynamic Mapping of Human Cortical Development during Childhood Through Early Adulthood. Proceedings of the National Academy of Sciences of the USA, 101, 8174-8179.

Gómez, R. (2012). Correlated Trait-Correlated Method Minus One Analysis of the Convergent and Discriminant Validities of the Strengths and Difficulties Questionnaire. Assessment, 21, 372-382. doi:10.1177/1073191112457588

Goñi, E., Esnaola, I., Rodríguez, A., \& Camino, I. (2015). Personal selfconcept and satisfaction with life in adolescence, youth and adulthood. Psicothema, 27, 52-58. http://doi.org/10.7334/psicothema2014.105

Goodman, R. (1997). The Strengths and Difficulties Questionnaire: A Research Note. Journal of Child Psychology and Psychiatry, 38(5), 581-586.

Halpern-Meekin, S. C., Manning, W. D., Giordano, P. C., \& Longmore, M. A. (2013). Relationship Churning in Emerging Adulthood: On/Of Relationships and Sex with an Ex. Journal of Adolescent Research, 28(2), 166-188.

He, J. P., Burstein, M., Schmitz, A., \& Merikangas, K. R. (2013). The Strengths and Difficulties Questionnaire (SDQ): the Factor Structure and Scale Validation in U.S. Adolescents. Journal of Abnormal Child Psychology, 41(4), 583-595. doi:10.1007/s10802-012-9696-6

IBM Corp. Released. (2013). IBM SPSS Statistics for Windows. Version 22.0. Armonk, NY: IBM Corp.

Junttila, N., \& Vauras, M. (2014). Latent profiles of parental self-efficacy and children's multisource-evaluated social competence. British Journal of Educational Psychology, 84(Pt 3), 397-414. doi:10.1111/bjep.12040

Kays, J. L., Hurley, R. A., \& Taber, K. H. (2012). The dynamic brain: neuroplasticity and mental health. Journal of Neurosychiatry and Clinical Neurosciences, 24, 118-124.
Koskelainen, M., Sourander, A., \& Vauras, M. (2001). Self-reported strengths and difficulties in a community sample of Finnish adolescents. European Child \& Adolescent Psychiatry, 10, 180-185.

Leff, S. S., Baker, C. N., Waasdorp, T. E., Vaughn, N. A., Bevans, K. B., Thomas, N. A., . . Monopoli, W. J. (2014). Social cognitions, distress, and leadership self-efficacy: associations with aggression for high-risk minority youth. Developmental Psychopatholy, 26(3), 759-772. doi:10.1017/s0954579414000376

Lien, L., Green, K., Welander-Vatn, A., \& Bjertness, E. (2009). Mental and somatic health complaints associated with school bullying between 10th and 12th grade students; results from cross sectional studies in Oslo, Norway. Clinical Practice and Epidemiology in Mental Health, 5(6), 1 8. doi:10.1186/1745-0179-5-6

Luengo Kanacri, B. P., Pastorelli, C., Eisenberg, N., Zuffiano, A., Castellani, V., \& Caprara, G. V. (2014). Trajectories of prosocial behavior from adolescence to early adulthood: associations with personality change. Journal of Adolescence, 37(5), 701-713. doi:10.1016/j.adolescence.2014.03.013

Llorca Mestre, A., Mesurado, B., \& Samper García, P. (2014). El rol mediador de la empatía, la conducta prosocial y la conducta agresiva en la depresión y la ansiedad. Ansiedad y estrés, 20, 247-258.

McElhaney, K. B., Immele, A., Smith, F. D., \& Allen, J. P. (2006). Attachment organization as a moderator of the link between peer relationships and adolescent delinquency. Attachment \& Human Development, 8, 33-46.

Mestre, M. V., Carlo, G., Samper, P., Tur-Porcar, A. M., \& Mestre, A. L. (2015). Psychometric Evidence of a Multidimensional Measure of Prosocial Behaviors for Spanish Adolescents. Journal of Genetics Psychology, 176(4), 260-271. doi:10.1080/00221325.2015.1052726

Moscoso, A., Jovanovic, N., \& Rojnic, M. (2015). Transition from adolescent to adult mental health services in Europe from the provider's perspective. Lancet Psychiatry, 2(9), 779 780. doi:doi: 10.1016/S2215 0366(15)00359 4.

Navarro-González, D., Lorenzo-Seva, U., \& Vigil-Colet, A. (2016). How response bias affects the factorial structure of personality self-reports. Psicothema, 28, 465-470.

Ogden, T. (2001). The prevention and management of behaviour difficulties in school. Research and practice. In J. Visser, H. Daniels, \& T. Cole (Eds.), Emotional and behavioural difficulties in mainstream schools (pp. 75-89). Oxford: Elsevier Science.

Ortuño-Sierra, J., Fonseca-Pedrero, E., Paino, M., \& Aritio-Solana, R. (2014). Prevalencia de síntomas emocionales y comportamentales en adolescentes españoles Prevalence of emotional and behavioural symptoms in spanish adolescents]. Revista de Psiquiatría y Salud Mental, 7, 121-130.

Ortuño-Sierra, J., Fonseca-Pedrero, E., Paino, M., Sastre i Riba, S., \& Muñiz, J. (2015a). Screening mental health problems during adolescence: Psychometric properties of the Spanish version of the Strengths and Difficulties Questionnaire. Journal of Adolescence, 38, 4956.

Ortuño-Sierra, J., Fonseca-Pedrero, J., Aritio-Solana, R., Moreno, A., Chocarro de Luis, E., Schumann, G., . . . and the IMAGEN consortium. (2015b). New Evidence of Factor Structure and Measurement Invariance of the SDQ Across Five European Nations. European Child and Adolescent Psychiatry. doi:DOI: 10.1007/s00787-0150729-x

Pakaslahti, L., Karjalainen, A., \& Keltikangas-Jarvinen, L. (2002). Relationships between adolescent prosocial problem-solving strategies, prosocial behaviour and social acceptance. International Journal of Behavioural Development, 26, 137-144.

Petrides, K. V., Frederickson, N., \& Furnham, A. (2004). The role of trait emotional intelligence in academic performance and deviant behaviour at School. Personality and Individual Differences, 36, 277-293.

Piehler, T. F. (2011). Peer Influence. In B. B. Brown \& M. J. Prinstein (Eds.), Encyclopedia of Adolescence (Vol. 2). Oxford: Elsevier.

Polanczyk, G. V., Salum, G. A., Sugaya, L. S., Caye, A., \& Rohde, L. A. (2015). Annual research review: A meta-analysis of the worldwide prevalence of mental disorders in children and adolescents. Journal of 
Child Psychology and Psychiatry, 56(3), 345-365. doi:doi: $10.1111 /$ jcpp. 12381

Poulou, M. (2014). How are trait emotional intelligence and social skills related to emotional and behavioural difficulties in adolescents? Educational Psychology: An International Journal of Experimental Educational Psychology, 34(3), 354-366. doi:doi:10.1080/01443410.2013.785062

Riglin, L., Thapar, A., Shelton, K. H., Langley, K., Frederickson, N., \& Rice, F. (2015). Profiling depression in childhood and adolescence: the role of conduct problems. J Child Psychol Psychiatry. doi:10.1111/jcpp.12465

Roisman, G. I., Masten, A. S., Coatsworth, J. D., \& Tellegen, A. (2004). Salient and Emerging Developmental Tasks in the Transition to Adulthood. Child Development, 75, 123-133.

Rønning, J. A., Helge Handegaard, B. H., Sourander, A., \& Mørch, W.-T. (2004). The Strengths and Difficulties Self-Report Questionnaire as a screening instrument in Norwegian community samples. European Child \& Adolescent Psycbiatry, 13, 73-82. doi: 10.1007/s00787-004-0356-4

Ruchkin, V., Jones, S., Vermeiren, R., \& Schwab-Stone, M. (2008). The Strengths and Difficulties Questionnaire: The Self-Report Version in American Urban and Suburban Youth. Psychological Assessment, 20(2), $175-182$

Salmera-Aro, K. (2011). Stages of Adolescence. In B. Bradford Brown \& M. J. Prinstein (Eds.), Encyclopedia of Adolescence (Vol. 1, pp. 360-368). Oxford: Elsevier.

Scott, S., Briskman, J., Woolgar, M., Humayun, S., \& O'Connor, T. G. (2011). Attachment in adolescence: Overlap with parenting and unique prediction of behavioral adjustment. Journal of Child Psychology and Psychiatry, 52, 1052-1062.
Sonunga-Barke, E. J. S., Thompson, M., Stevenson, J., \& Viney, D. (1997). Patterns of behaviour problems among pre-school children. Psychological Medicine, 27, 909-918.

Statistical Package for the Social Sciences. (2006). SPSS Base 15.0 User's Guide. Chicago, IL: SPSS Inc.

Steinberg, L. (2013). The influence of neuroscience on US Supreme Court decisions about adolescents' criminal culpability. Nature Reviens Neuroscience, 14, 513-518. doi:doi:10.1038/nrn3509

Uggen, C., \& Massoglia, M. (2003). Desistance from crime and deviance as a turning point in the life course. In J. T. Mortimer \& M. J. Shanahan (Eds.), Handbook of the life course (pp. 311-329). New York: Plenum.

Van Roy, B., Grøholt, B., Heyerdahl, S., \& Clench-Aas, J. (2010). Understanding discrepancies in parent-child reporting of emotional and behavioural problem: Effects of relational and socio-demographic factors. BMC Psychiatry, 10(56). doi:doi:10.1186/1471-244X-10-56

van Widenfelt, B. M., Goedhart, A. W., Treffers, P. D., \& Goodman, R. (2003). Dutch version of the Strengths and Difficulties Questionnaire (SDQ). European Cbild \& Adolescent Psychiatry, 12, 281-289.

Worthman, C. M. (2011). Hormones and Behavior. In B. B. Brown \& M. J. Prinstein (Eds.), Encyclopedia of Adolescence (Vol. 1, pp. 177-192). Oxford: Elsevier.

Yao, S., Zhang, C., Zhu, X., Jing, X., McWhinnie, C. M., \& Abela, J. R. Z (2009). Measuring Adolescent Psychopathology: Psychometric Properties of the Self-Report Strengths and Difficulties Questionnaire in a Sample of Chinese Adolescents. Journal of Adolescent Health, 45, 5562

(Article received: 13-04-2015; revised: 13-11-2015; accepted: 19-11-2015) 